\title{
Effects of training on resident physician emergency airway management skills
}

\author{
Emily H. Garmon, MD (D) Eileen M. Stock, PhD • Alejandro C. Arroliga, MD • \\ Jolene D. Bean-Lijewski, MD
}

Received: 4 November 2016/Revised: 12 February 2017/Accepted: 21 February 2017/Published online: 28 February 2017

(c) Canadian Anesthesiologists' Society 2017

\section{To the Editor,}

Emergency airway management is necessary when patients develop acute cardiopulmonary failure. Early intubation prevents hypoxemia from a poor bag-mask seal, but multiple intubation attempts increase the risk of complications. ${ }^{1-3}$ The Canadian Airway Focus Group summarizes the adverse effects associated with multiple intubation attempts in Table 3 of their 2013 publication on difficult tracheal intubation in the unconscious patient. ${ }^{4}$ Highly trained residents in supervised intensive care settings have previously been studied. ${ }^{1-3}$

In our teaching hospital, resident physicians and nurses on a "code" team respond to hospital ward cardiopulmonary resuscitation events. Resident physicians lacking extensive airway management training are immediately available and provide initial airway management, including direct laryngoscopy and endotracheal intubation. Thereafter, an anesthesiology resident arrives from the operating room to provide further airway assistance with direct laryngoscopy or advanced airway adjuncts, if needed.

E. H. Garmon, MD $(\bowtie) \cdot$ J. D. Bean-Lijewski, MD

Department of Anesthesiology, Baylor Scott \& White Health, Temple, TX, USA

E. H. Garmon, MD - E. M. Stock, PhD .

A. C. Arroliga, MD - J. D. Bean-Lijewski, MD

Texas A\&M Health Science Center College of Medicine, Bryan, TX, USA

\section{E. M. Stock, $\mathrm{PhD}$}

Center for Applied Health Research, Baylor Scott \& White Health, Temple, TX, USA

A. C. Arroliga, MD

Pulmonary Department, Baylor Scott \& White Health, Temple, TX, USA
Following institutional review board approval, we conducted a prospective, observational study that compared success and complication rates between experienced and inexperienced resident physicians. The code nurse completed a specifically designed event form for adult ward patients intubated during a code from June 2009 through January 2013. Missing event forms were completed using the subject's resuscitation code form, medical record, and discussion with the code team. Two groups were defined in terms of their expertise:

1. Anesthesiology residents in postgraduate training year two and above $v s$ all others (designated nonanesthesiology residents); and

2. Upper-level residents (all residents in postgraduate year two and above) vs lower-level residents.

In all, 218 subjects were intubated, among whom 60 required multiple attempts (laryngoscope removed from the oropharynx and subsequently replaced or a new adjunct utilized). Subject demographics were similar. Experience in both training field and training level improved intubation success and reduced esophageal intubation. Overall, 70 of 218 (32\%) of subjects experienced complications, including esophageal intubation, regurgitation, and/or aspiration (Table ). Subjects with body mass index $>35$ $\mathrm{kg} \cdot \mathrm{m}^{-2}$ had a fourfold increased risk for requiring more than two intubation attempts (relative risk [RR], 4.2; 95\% confidence interval $[\mathrm{CI}], 2.0$ to 8.8$)$. Mortality rates were similar for the physician groups. In all, 139 of 218 (64\%) of subjects were in pulseless arrest prior to intubation Their 28-day survival was significantly less than that for subjects not in pulseless arrest $(n=22 / 138$ [16\%] vs $n=47 / 77$ [61\%]; $P<0.01)$.

To our knowledge, this is the first study to compare intubation success and complication rates for resident 
Table Patient demographics and status of first-intubation care provider attempts ( $n=218$ patients)

\begin{tabular}{|c|c|c|c|c|c|}
\hline \multirow[b]{2}{*}{ Parameter } & \multirow{2}{*}{$\begin{array}{l}\text { Total cohort } \\
(n=218) \\
n(\%)\end{array}$} & \multicolumn{2}{|c|}{ First attempt by training level } & \multicolumn{2}{|c|}{ First attempt by training specialty } \\
\hline & & $\begin{array}{l}\text { PGY 1 } \\
(n=37)\end{array}$ & $\begin{array}{l}\mathrm{PGY} \geq 2 \\
(n=181)\end{array}$ & $\begin{array}{l}\text { Non-anesthesiology } \\
(n=122)\end{array}$ & $\begin{array}{l}\text { Anesthesiology } \\
(n=96)\end{array}$ \\
\hline Age, mean (SD) & $66.0(14.9)$ & $67.5(15.9)$ & $65.7(14.8)$ & $66.0(15.5)$ & $66.1(14.3)$ \\
\hline Female sex & $107(49 \%)$ & $17(46 \%)$ & $90(50 \%)$ & $61(50 \%)$ & $46(48 \%)$ \\
\hline \multicolumn{6}{|l|}{ Reason for intubation } \\
\hline Cardiac arrest & $139(64 \%)$ & $17(46 \%)$ & $122(67 \%)$ & $57(47 \%)$ & $82(86 \%)$ \\
\hline Respiratory failure & $29(13 \%)$ & $7(19 \%)$ & $22(12 \%)$ & $25(20 \%)$ & $4(4 \%)$ \\
\hline Other (neurologic, mixed) & $23(11 \%)$ & $8(22 \%)$ & $15(8 \%)$ & $18(15 \%)$ & $5(5 \%)$ \\
\hline Not indicated & $27(12 \%)$ & $5(13 \%)$ & $22(12 \%)$ & $22(18 \%)$ & $5(5 \%)$ \\
\hline \multicolumn{6}{|l|}{ Intubation technique } \\
\hline Direct laryngoscopy & $209(96 \%)$ & $33(89 \%)$ & $176(97 \%)$ & $117(96 \%)$ & $92(96 \%)$ \\
\hline Other & $9(4 \%)$ & $4(11 \%)$ & $5(3 \%)$ & $5(4 \%)$ & $4(4 \%)$ \\
\hline \multicolumn{6}{|l|}{ Number of intubation attempts } \\
\hline One & $158(72 \%)$ & $16(43 \%)$ & $142(78 \%)$ & $80(66 \%)$ & $78(81 \%)$ \\
\hline Two & $33(15 \%)$ & $12(32 \%)$ & $21(12 \%)$ & $21(17 \%)$ & $12(13 \%)$ \\
\hline$\geq 3$ & $27(12 \%)$ & $9(24 \%)$ & $18(10 \%)$ & $21(17 \%)$ & $6(6 \%)$ \\
\hline \multicolumn{6}{|l|}{ Complications } \\
\hline Esophageal intubation & $42(19 \%)$ & $14(37 \%)$ & $28(15 \%)$ & $34(28 \%)$ & $8(8 \%)$ \\
\hline Regurgitation & $35(16 \%)$ & $6(16 \%)$ & $29(16 \%)$ & $19(16 \%)$ & $16(17 \%)$ \\
\hline Aspiration & $26(12 \%)$ & $5(14 \%)$ & $21(12 \%)$ & $15(12 \%)$ & $11(11 \%)$ \\
\hline
\end{tabular}

$\mathrm{PGY}=$ postgraduate year; $\mathrm{SD}=$ standard deviation

physicians in lower acuity units without routine faculty supervision. Our results show that experience improves intubation success and that the need for more than two intubation attempts increases the risk of both regurgitation (RR, 2.9; 95\% CI, 1.6 to 5.4) and intubation trauma/ bleeding (RR, 5.4; 95\% CI, 1.5 to 12.1). They further suggest that experience gained during the first postgraduate year of residency increases success later. Limitations include observer, reporter, or recall bias during event form completion. Furthermore, hemodynamic and pulmonary complications were not recorded, and there was no adjustment for confounding.

This study inspired a multidisciplinary team to consider ways to improve first responder performance. We considered requiring resident physicians to demonstrate intubation proficiency in a supervised setting prior to code team participation, but proficiency requires an average of 50 supervised attempts. ${ }^{5}$ Concern was raised that this requirement for such a large number of residents could limit intubation opportunities for other airway management trainees (anesthesiology/emergency medicine residents, prehospital emergency trainees). Ultimately, we balanced resident physician training objectives with patient safety. Experience improves tracheal intubation success, and lowerlevel residents gain experience with intubations during emergency code events. The institutional guideline permits lower-level residents one intubation attempt in patients without cardiac arrest. After one failed attempt, intubation must be performed by the most experienced physician available. Lower-level residents are not permitted to attempt intubation in cardiac arrest patients if an anesthesia resident is available. Ongoing quality improvement efforts should also focus on other interventions known to improve safety. These measures include incorporating a pre-intubation checklist and improving the availability of equipment and experts familiar with multiple intubation techniques.

Conflicts of interest None.

Editorial responsibility This submission was handled by Dr. Gregory L. Bryson, Deputy Editor-in-Chief, Canadian Journal of Anesthesia.

Financial disclosures None.

Other associations None.

\section{References}

1. Benedetto WJ, Hess DR, Gettings E, et al. Urgent tracheal intubation in general hospital units: an observational study. J Clin Anesth 2007; 19: 20-4.

2. Griesdale DE, Bosma TL, Kurth T, Isac G, Chittock DR. Complications of endotracheal intubation in the critically ill. Intensive Care Med 2008; 34: 1835-42. 
3. Mort TC. Emergency tracheal intubation: complications associated with repeated laryngoscopic attempts. Anesth Analg 2004; 99: 607-13.

4. Law JA, Broemling N, Cooper RM, et al.; Canadian Airway Focus Group. The difficult airway with recommendations for management-part 1-difficult tracheal intubation encountered in an unconscious/induced patient. Can J Anesth 2013; 60: 1089-118. 5. Mulcaster JT, Mills J, Hung OR, et al. Laryngoscopic intubation: learning and performance. Anesthesiology 2003; 98: 23-7. 